\title{
A METHOD FOR LINKING SAFETY FACTOR TO THE TARGET PROBABILITY OF FAILURE IN FIRE SAFETY ENGINEERING
}

\author{
Depeng KONG ${ }^{\mathrm{a}, \mathrm{b}}$, Shouxiang LU ${ }^{\mathrm{a}}$, Håkan FRANTZICH ${ }^{\mathrm{c}}, \mathrm{S} . \mathrm{M} . \mathrm{LO}^{\mathrm{b}}$ \\ ${ }^{a}$ State Key Laboratory of Fire Science, University of Science and Technology of China, \\ Hefei, People's Republic of China \\ ${ }^{b}$ Department of Civil and Architectural Engineering, City University of Hong Kong, \\ Kowloon Tang, Hong Kong \\ ${ }^{c}$ Department of Fire Safety Engineering and System Safety, Lund University, Lund, Sweden
}

Received 02 Apr 2012; accepted 16 Aug 2012

\begin{abstract}
Ensuring occupants' safety in building fires is one of the most important aspects for fire safety engineering. Many uncertainties are inevitably introduced when estimating the occupant safety level, due to the high complexity of fire dynamics and the human behaviour in fires. Safety factor methods are traditionally employed to deal with such uncertainties. This kind of methods is easy to apply but leaves fire safety engineers unsure of the margin by which the design has failed. A method of linking safety factor and probability of failure in fire safety engineering is proposed in this study. An event tree is constructed to analyse potential fire scenarios that arise from the failure of fire protection systems. Considering uncertainties related to fire dynamics and evacuation, the traditional deterministic safety factor is considered as a random variable. Because there is no target probability of failure accepted by the whole fire safety engineering community, the concept of expected risk to life (ERL) is integrated to determine the target probability of failure. This method employs a Monte Carlo Simulation using Latin Hypercube Sampling (LHS) to calculate the required safety factor. A practical case study is conducted using the method proposed in this study.
\end{abstract}

Keywords: probability of failure, safety factor, Monte Carlo simulation, fire safety engineering, uncertainty analysis.

Reference to this paper should be made as follows: Kong, D.; Lu, S.; Frantzich, H.; Lo, S. M. 2013. A method for linking safety factor to the target probability of failure in fire safety engineering, Journal of Civil Engineering and Management 19(Supplement 1): S212-S221. http://dx.doi.org/10.3846/13923730.2013.802718

\section{Introduction}

The rapid development of big cities in China has seen the construction of a large number of high-rise buildings. Due to the complexity of such buildings and the large number of occupants in them, once fire occurs, people may have difficulty evacuating and suffer injuries or death. Many large fires have occurred recently with high death tolls (Guo, Fu 2007). For example, a fire at Dongdu Mansion in Luoyang, Henan province on $25^{\text {th }}$ Dec. 2000 caused 309 deaths. Forty-four deaths and 88 injuries resulted from the fire that occurred in a club in Shenzhen, Guangdong province on $20^{\text {th }}$ Sep. 2008. On $15^{\text {th }}$ Nov. 2010 , a fire that occurred in an apartment building in Shanghai caused 58 fatalities and 71 injuries. One of the most essential requirements for fire safety implementation in a building is safe evacuation from building in the event of fire (Papinigis et al. 2010). Reasonable fire safety design and management are two measures essential to achieving this goal. Fire safety management mainly deals with the phase when the building is ready to be used (i.e. excluding the construction phase), and can be enhanced by keeping the fire load density low, allowing the fire protection system to work well. As regards of the fire safety design, performance based fire protection design (PFPD) is now increasingly employed for high rise buildings as an alternative to prescriptive fire protection design (Hadjisophocleous et al. 1998). In PFPD, two types of timelines are compared to determine the occupants' safety level: available safe egress time (ASET) and required safe egress time (RSET), as shown in Figure 1. Occupants are believed to be safe if the former is larger than the latter. Otherwise, fatalities may occur. ASET is usually estimated by applying fire dynamic models with userspecified input while RSET is generally estimated by using evacuation models or analytical calculations (Nelson, Mowrer 2002). Research in the field of the calculation of ASET relies on physical factors, while the calculation of RSET mainly depends on human behaviour. Due to the complexity of fire dynamics and human behaviour during the evacuation from fires, ASET and RSET are subject to uncertainties (Magnusson et al. 1996). The uncertainties associated with ASET and RSET during calculation are an important consideration if reasonable PFPD results are to be obtained. 


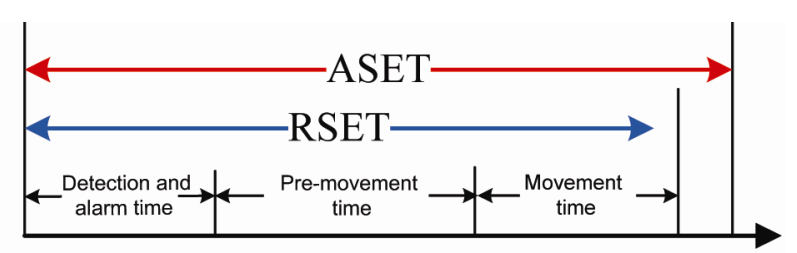

Ignition

Fig. 1. Timeline for evacuation in building fires

There are two main methods of factoring uncertainties into fire safety engineering. The traditional method considers the safety factor. This method is generally employed by considering a limited number of fire scenarios using deterministic methods. The selected fire scenarios are considered to represent the most likely or most severe scenarios. All possible uncertainties associated with design parameters are determined and deterministic values for these uncertain parameters are employed. Fire safety engineers then evaluate these uncertainties using their experience and assign a safety factor to represent each one. ASET is compared with the product of the assigned safety factor and RSET. Hence, the safety factor method can be considered a deterministic method. Safety factors have been widely employed in fire safety engineering due to their simplicity. However, the selection of safety factors is subjective and depends heavily on the fire safety engineers' experience. Such subjective selection is difficult to confirm or disprove and may introduce additional uncertainties into results, leaving decision makers dissatisfied with the results. Furthermore, even if a sufficiently accurate safety factor can be assigned, the probability of failure and fire risk still cannot be quantified: this method leaves fire safety engineers unsure of the margin by which a design has failed. Correspondingly, the changes which must be made to satisfy the required safety level and how best to effect these changes are also unknown.

Probability-based methods have been proposed as an alternative way to allow for uncertainties in fire safety engineering. Such methods allow available uncertain data to be incorporated into ASET and RSET and evaluate the probability of failure, i.e. the probability of ASET being smaller than RSET. One probabilistic method, the Beta method (Frantzich 1998), is increasingly accepted in fire safety engineering. Although the probability-based approaches are superior to the safety factor method when considering uncertainties, they are seldom employed by fire safety engineers, many of whom fear that such methods will prove complex (He 2010). Therefore, we seek to propose a method which will combine the best features of safety factor and probability methods, in order to provide fire safety engineers with a guide to selecting reasonable safety factors. The proposed method should be able to answer the following two questions:

(1) What is the probability of failure of a given safety factor?

(2) How large a safety factor should be assigned to ensure the required acceptable probability of failure falls within the required range?

Even though the necessity of relating safety factors and probability of failure in fire safety engineering has long been recognized, progress in this research area has been very slow.

Ramachandran (1995) proposed a method of calculating the safety factor when the mean and standard deviation of fire resistance and severity are known. In this study, both fire resistance and severity are simply considered as two normally distributed variables. He (2010) made some attempts to link safety factor and probability of failure in performance-based fire protection design. He found that the probability of failure is not only a function of the safety factor, but also depends on other parameters, such as the variation coefficient of RSET. However, as in Ramachandran's study, ASET and RSET are simply treated as two uncertain parameters in He's work, rather than a function of uncertain input parameters, such as fire growth rate and pre-movement time.

In general, ASET and RSET cannot be described by only two random variables, but rather by functions of a set of random variables. Hence, a method of linking safety factors and the target probability of failure is proposed in this study, in which ASET and RSET are described by functions of a set of uncertain input parameters. Since fire scenario design is essential to fire safety engineering, the event tree method is employed to construct possible fire scenarios. Considering uncertainties associated with ASET and RSET, the safety factor is treated as a random variable, rather than a traditional deterministic variable. Then a specific safety factor can be identified on its probability distribution, whose probability corresponds to the target probability of failure. Monte Carlo Simulation is employed to calculate the safety factor corresponding to a target probability of failure.

The following sections describe the steps of the proposed method. In Section 1, probable fire scenarios from an event tree are analysed with consideration of the reliability of fire protection systems. In Section 2, the calculation method for the safety factor corresponding to the target probability of failure is illustrated. A method of setting the target probability of failure with regard of the expected risk to life is proposed. The concept of the random safety factor and a method of calculating the safety factor based on Monte Carlo simulation are also described in this section. In Section 3, a case study is given to demonstrate the method in detail. The final section presents the conclusions and a discussion of future research.

\section{Fire scenario analysis based on event tree}

Designing appropriate fire scenarios is very important in PFPD and fire risk analysis. The traditional approach is to select one or a few "credible worst scenarios". A set of ASET and RSET is calculated for these scenarios to determine the safety level. This method seemingly makes sense. However, it is difficult to select a "credible worst scenario" which is agreed on by all stakeholders. As there are many factors influencing fire spread and smoke movement, such as fuel characteristics, building geometry and fire protection systems, various fire scenarios may occur. For a given building, the fire scenarios differ significantly depending on whether the fire protection 


\begin{tabular}{|c|c|c|c|c|}
\hline Fire ignition & Sprinkler & $\begin{array}{c}\text { Smoke automatic } \\
\text { detection and alarm }\end{array}$ & $\begin{array}{c}\text { Manual detection } \\
\text { and alarm }\end{array}$ & Scenario \\
\hline
\end{tabular}

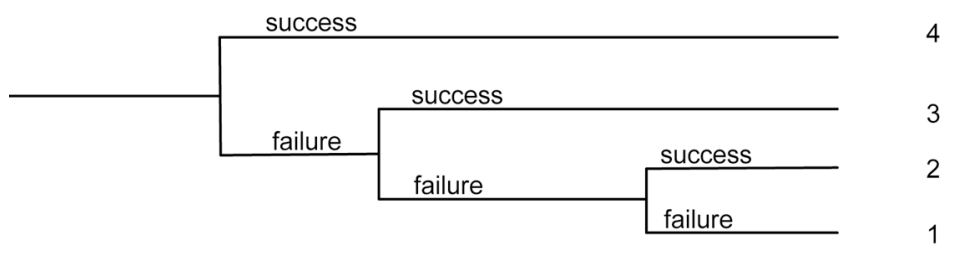

Fig. 2. Fire scenario generated by event tree

systems, such as sprinklers and smoke control, function as expected. Hence, the reliability of fire protection systems plays an important role in the occurrence of different fire scenarios (Chu 2007). When considering the influence of the reliability of fire protection systems on different fire scenarios, the event tree method is employed to generate various fire scenarios according to the success or failure of these fire protection systems. Given that the majority of casualties in fires are caused by inhalation of smoke, three basic events influencing smoke movement are considered here: sprinklers, automatic smoke detection and alarm, and manual smoke detection. The fire scenarios generated by event tree are displayed in Figure 2.

\section{Calculation of safety factors to target probability of failure}

\subsection{The target probability of failure}

As stated above, the safety level of occupants in building fires is evaluated by comparing ASET and RSET. Where ASET is smaller than RSET, fatalities may occur. If we define the safety margin as follows:

$$
G=A S E T-R S E T \text {. }
$$

Failure occurs when $G<0$. The equation $G=0$ is defined as the limit state equation. More details of the limit state equation can be found in Magnusson et al. (1996).

Due to the complexity of fire dynamics and the human behaviour during the evacuation from fires, there are many uncertainties associated with the input parameters, which make ASET and RSET uncertain. Considering these uncertainties, the limit state equation can be formulated as:

$$
g\left(X_{1}, X_{2}, \cdots, X_{M}\right)=0,
$$

where: $X_{1}, X_{2}, \cdots, X_{M}$ are uncertain parameters, such as fire growth rate and occupant pre-movement time.

The function form of $g$ is usually unknown explicitly or very complicated, the response surface method may be employed to derive the relationship between the uncertain input parameters and the output. An introduction of response surface method is presented by Myers and Montgomery (2002).

If uncertainties relating to ASET and RSET are considered, the event that ASET is smaller than RSET, i.e. the failure of occupants to escape to safety, should also be uncertain. The probability of failure exists if the distributions of ASET and RSET overlap, as shown in Figure 3. The probability of failure can be determined as:

$$
p=\int_{g(\mathbf{X})<0} f_{\mathbf{X}}(\mathbf{x}) d \mathbf{x},
$$

where: $p$ is the probability of failure; and $f_{\mathbf{X}}(\mathbf{x})$ is the joint probability density function of the uncertain parameters $\mathbf{X}=\left(X_{1}, X_{2}, \cdots, X_{M}\right)$.

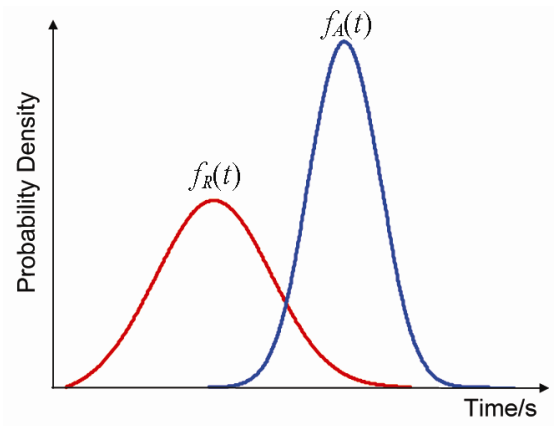

Fig. 1. A schematic representation of uncertain ASET and RSET

In order to ascertain the safety factor corresponding to the target probability of failure, the first step is to determine the target probability of failure. There is currently no generally accepted target probability of failure, so a method of determining this target probability, integrating expected risk to life (ERL), is proposed in this study.

Fire risk to life can be measured as the combination of the occurrence probability and the number of casualties in a fire scenario (Sekizawa 2005), and can be expressed as follows:

$$
\operatorname{Risk}_{i}=C_{i} \cdot f_{i} \text {, }
$$

where: $f_{i}$ is the probability of fire scenario $i$ occurring; and $C_{i}$ is the number of casualties for fire scenario $i$.

When calculating the occurrence probability of a fire scenario, the first step is to determine the occurrence probability of basic events, in this case, activation of the fire protection systems. The occurrence probability of basic events can be broadly equated with the operational reliability of the fire protection systems. Although it is still difficult to acquire the accurate operational reliability data, some data are available from several sources, such 
as fire reports and maintenance records. Using the event tree shown in Figure 2 and the operational reliability of the fire protection systems, the occurrence probability of each fire scenario can be estimated.

According to He et al. (2002a), the number of casualties of fire scenario $i, C_{i}$, may be determined as follows:

$$
C_{i}=N_{p} \cdot p_{i}
$$

where: $N_{p}$ is the number of occupants in the building and $p_{i}$ is the probability of failure of fire scenario $i$. In addition, the expected risk to life is defined as follows:

$$
E R L=\frac{f_{i g} \cdot \operatorname{Risk} \cdot A}{N_{p}},
$$

where: $f_{i g}$ is the fire ignition frequency, $/\left(\mathrm{m}^{2} \cdot\right.$ year $)$ and $A$ is the area of the building, $\mathrm{m}^{2}$. Substituting Eqns (4) and (5) into Eqn (6), the target probability of failure, $p_{t i}$, can be determined as follows:

$$
p_{t i}=\frac{E R L_{a c c}}{f_{\text {ig }} f_{i} A},
$$

where: $E R L_{a c c}$ is the acceptable $E R L$. Once the acceptable $E R L$ has been determined, the target probability of failure can be obtained. Hence, the only concern is to find an acceptable $E R L$ value.

Although code equivalency is one potential method of determining this value, it would involve a difficult task, due to the complexity and multiplicity of existing fire codes (Tanaka 2011). Another possibility is to use fire statistical data. When fire statistics are employed to determine an acceptable $E R L$ value, it should be noted that acceptable $E R L$ may vary among different societies. In this paper, the acceptable ERL calculated by the fire statistical data service in Beijing is adopted.

\subsection{The random safety factor}

As stated above, both ASET and RSET are associated with uncertainties. In order to allow for these uncertainties, fire safety engineers normally introduce a safety factor, $\lambda$, which is usually defined as the ratio of ASET to RSET:

$$
\lambda=\frac{A S E T}{R S E T} .
$$

Traditionally, the safety factor is a deterministic parameter and its value is determined by fire safety engineers' subjective judgment based on their experience. However, the safety factor should be a random parameter rather than a deterministic one as both ASET and RSET are associated with uncertainties. In this way, the safety factor may be characterized by a certain distribution form as follows:

$$
\lambda=\frac{A S E T}{R S E T} \sim D\left(\mu, \sigma^{2}\right),
$$

where: $D$ is the specific distribution form of $\lambda$, such as normal, uniform or log-normal distribution; $\mu$ and $\sigma$ are the mean and standard deviation of $\lambda$, respectively. Given a target probability of failure $p_{t i}$ for fire scenario $i$, a specific safety factor $\lambda_{i}^{*}$ can be identified along with its probabilistic distribution, of which the cumulative probability equals $p_{t i}$, i.e.:

$$
F_{\lambda}\left(\lambda_{i}^{*}\right)=P\left(\lambda \leq \lambda_{i}^{*}\right)=p_{t i},
$$

where: $F_{\lambda}$ is the cumulative distribution function of $\lambda$.

Using inverse transformation, the safety factor corresponding to the target probability of failure can be determined as follows:

$$
\lambda_{i}^{*}=F_{\lambda}^{-1}\left(p_{t i}\right) .
$$

Hence, once the safety factor distribution form is determined, it always corresponds to the safety factor for any specified target probability of failure.

\subsection{The calculation of the safety factor by Monte Carlo simulation using Latin Hypercube Sampling}

In order to calculate the safety factor corresponding to the target probability of failure, Monte Carlo simulation will be employed here. In Monte Carlo simulation, the probability of failure can be estimated as follows:

$$
p_{f i}=\frac{n}{N},
$$

where: $n$ is the number of samples for which $\lambda<1$, while $N$ is the sample size. In other words, in order to satisfy the probability of failure, the number of samples which fail should be no more than $n$, i.e.:

$$
n=p_{f i} \cdot N .
$$

The required safety factor can be determined as follows (Qu, Haftka 2004):

$$
\lambda^{*}(n)=n^{\text {th }} \min \left\{\lambda_{1}, \lambda_{2}, \cdots \lambda_{N}\right\},
$$

where: $n^{\text {th }} \min$ is the $n^{\text {th }}$ smallest safety factor among $N$ safety factors by Monte Carlo simulation. This suggests that in fact the calculation of the required safety factor only requires sorting the lowest safety factors according to the required probability of failure in Monte Carlo samples.

In practical fire safety engineering, the target probability of failure is usually very small, which means that the sample size of the Monte Carlo Simulation should be sufficiently large to obtain a good estimate of the corresponding safety factor. In this situation, efficient sampling technique is important for Monte Carlo Simulation. In this study, the use of Latin Hypercube Sampling (LHS) technique is recommended.

LHS is a type of stratified sampling technique, originally proposed by Mckay et al. (1979). With the advantage of efficient stratification, LHS allows a large amount of information to be extracted from a relatively 
small sample size. Moreover, LHS can generate random samples from the ranges of all possible values, thus giving insights into the tails of the probability distributions. LHS operates in the following manner to generate a sample size $N$ from input variables $x_{1}, x_{2}, \ldots, x_{M}$ with distributions $D_{1}, D_{2}, \ldots, D_{M}$. The random space for each input variable is exhaustively divided into $N$ non-overlapping intervals of equal probability. One value is then randomly selected from each interval, with cumulative probability taken into consideration. The $N$ values for $x_{1}$ are paired without replacement and in a random manner with the $N$ values of $x_{2}$. The $N$ pairs are combined randomly without replacement with $N$ values for $x_{3}$ to produce $N$ triples. This procedure continues until the set of all input variables is combined.

The method of calculating the safety factor corresponding to the target probability of failure proposed in this paper can be concluded as shown in the flowchart, Figure 4.

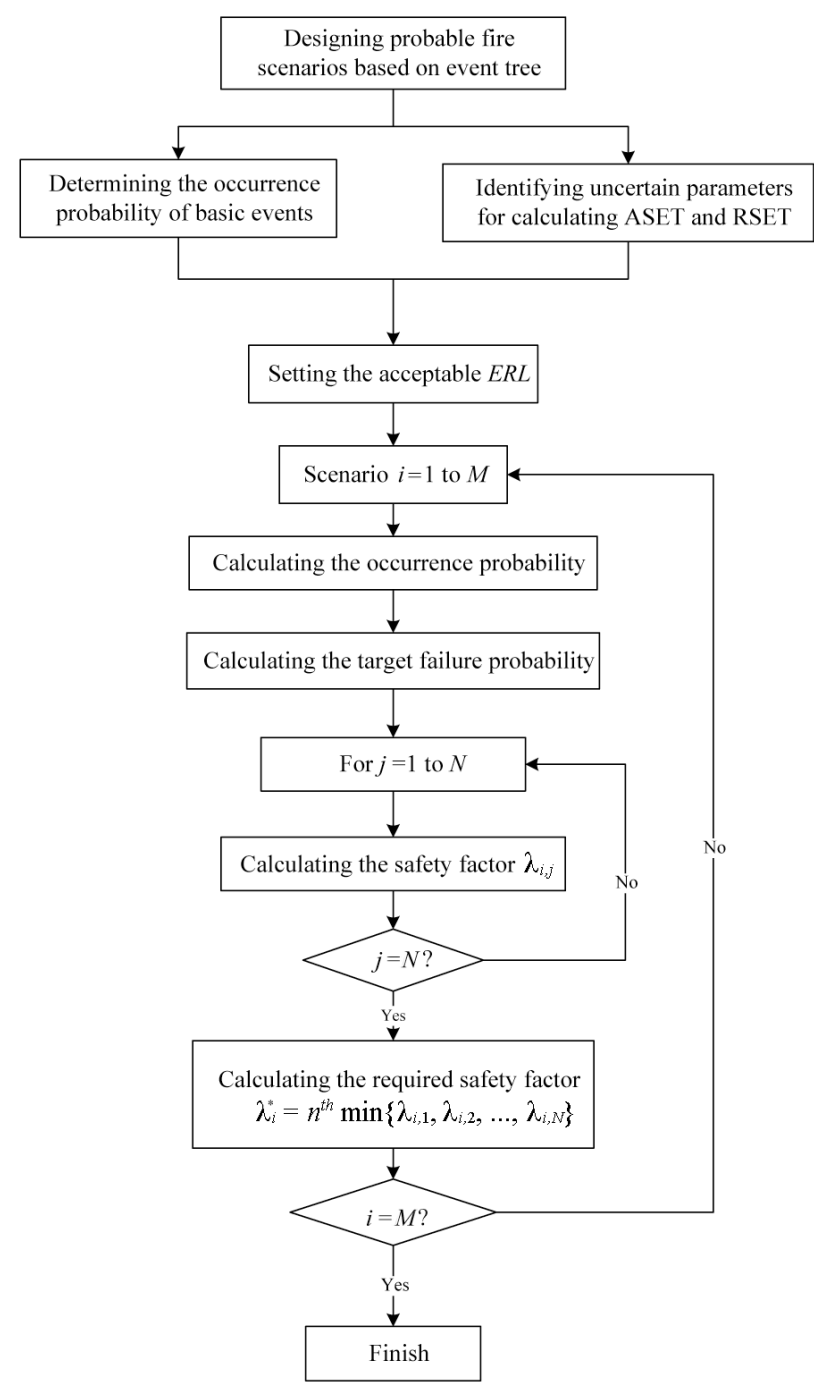

Fig. 2. The schematic framework for linking safety factors and target probability of failure

\section{Case study}

In order to demonstrate the method in more detail, a case study is presented. The building environment is a single fire compartment of a commercial building in accordance with the Chinese Code of Design on Building Fire Protection and Prevention (GB 50016-2006). The height for the single fire compartment is $6 \mathrm{~m}$ and the area is $1100 \mathrm{~m}^{2}$.

Using the event tree shown in Figure 2, four probable fire scenarios can be determined from the event tree analysis.

\subsection{Setting the target probability of failure}

As described in Section 2.1, the first step in setting the target probability of failure is to calculate the occurrence probability of each fire scenario. The occurrence probability of each basic event can be obtained from statistical data concerning the operational reliability of the fire protection systems, as shown in Table 1 (Bukowski et al. 1999). The occurrence probability of each fire scenario is calculated as shown in Table 2.

Table 1. Operational reliability of fire protection systems in the event tree (Bukowski et al. 1999)

\begin{tabular}{cc}
\hline Fire protection system & Operational reliability \\
\hline Sprinkler & 0.93 \\
Smoke detection & 0.72 \\
Manual detection & 0.70 \\
\hline
\end{tabular}

In order to determine the acceptable ERL, statistical fire data from Beijing are adopted. According to statistical fire data from Beijing from 1998 to 2004 (Fire Service Bureau 1998-2004), the annual fire casualty rate was $1.02 \times 10^{-5} /$ year. Since about $1.9 \%$ of total fire casualties results from commercial building fires, the fire casualty fate in commercial buildings can be estimated as $1.94 \times 10^{-7} /$ year, which can be considered as an acceptable ERL in this case.

We take $4.12 \times 10^{-6} /\left(\right.$ year $\left.\cdot \mathrm{m}^{2}\right)($ Ohmiya et al. 2002) as the fire ignition frequency. Using Eqn (7), the target probability of failure for each fire scenario can be estimated. The results are shown in Table 2.

Table 2. Occurrence probability and target probability of failure

\begin{tabular}{ccc}
\hline Fire scenario & $\begin{array}{c}\text { Occurrence } \\
\text { probability }\end{array}$ & $\begin{array}{c}\text { Target probability of } \\
\text { failure }\end{array}$ \\
\hline 1 & 0.00588 & $7.28 \times 10^{-3}$ \\
2 & 0.0132 & $3.24 \times 10^{-3}$ \\
3 & 0.0504 & $8.49 \times 10^{-4}$ \\
4 & 0.9300 & $4.60 \times 10^{-5}$ \\
\hline
\end{tabular}

\subsection{Calculating ASET and RSET with consideration of uncertainties}

ASET is usually calculated by fire dynamic models, such as field models and zone models. Field models are more accurate, but time-consuming. Compared with that of field models, the computation time of zone models is 
rather short; however, the results are less accurate. Nonetheless, zone models are still widely used in fire safety engineering because of their short computation time and acceptable level of accuracy. Since thousands of runs of fire models for Monte Carlo simulations are required, a two-zone model, CFAST, is adopted to predict fire and smoke movement.

In PFPD and fire risk analysis, thresholds should be defined to determine the tenability limit, i.e. ASET. The tenability criteria may be smoke layer height, temperature, visibility and/or toxicity. For example, British Standards (2003) deemed that the threshold for the onset of untenable conditions is usually an upper layer interface position $2.1 \mathrm{~m}$ above the floor, average upper layer temperature of $200^{\circ} \mathrm{C}$, or optical density of $0.1 \mathrm{~m}^{-1}$ with an upper layer interface position $2.1 \mathrm{~m}$ above the floor.

From the hazard standpoint, smoke descent to a chosen level may be a reasonable criterion (Peacock et al. 1993). Therefore, the time when smoke descends to $2.1 \mathrm{~m}$ is considered as an ASET in this paper.

For further simplification, the response surface for ASET is derived using data from CFAST (Magnusson et al. 1996). The simplified equation for ASET can be expressed by:

$$
A S E T=1.67 \alpha^{-0.26} H^{0.44} A^{0.54},
$$

where: $\alpha$ is the fire growth rate, $\mathrm{kW} / \mathrm{s}^{2} ; H$ is the height of the compartment, $\mathrm{m} ; A$ is the area of the compartment, $\mathrm{m}^{2}$. For a specific compartment, the height and area can be considered as deterministic.

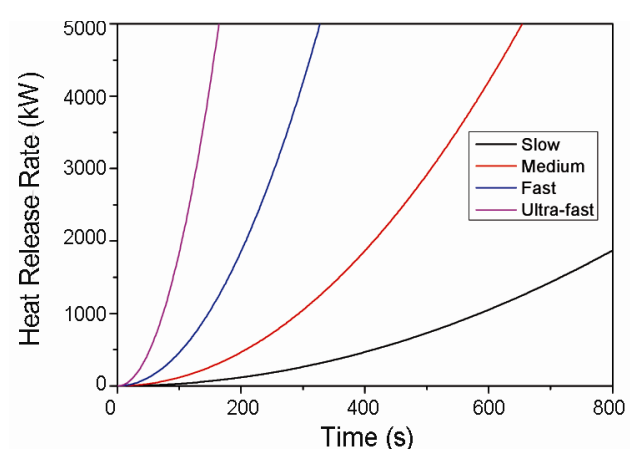

Fig. 3. Heat release rate curves of time-squared fire

The selection of fire growth rate is based on expert discretion, often from NFPA's slow, medium, fast and ultra-fast fires with the corresponding values of 0.00293 , $0.0117,0.0469$ and $0.188 \mathrm{~kW} / \mathrm{s}^{2}$, respectively (NFPA 1998). The corresponding heat release rate curves are illustrated in Figure 5. However, as Morgan (1998) notes, for a given occupancy there will in fact be a distribution of possible fire growth curves, depending on factors such as variation in fuel layout and location of the initial ignition, etc. Holborn et al. (2004) suggested the observed fire growth rates for a range of different occupancy types were reasonably well approximated by log-normal distributions, based on Greater London Area data from real fire incidents. Deguchi et al. (2011) analysed data for fire growth time and burned area in national fire statistics from Japan and obtained the distributions for fire growth rates in real fire situations. They also discovered that the distributions for fire growth rate in four kinds of buildings, namely, offices, residences, restaurants and stores, follow a log-normal distribution. Log-normal distribution is therefore employed to characterize uncertainty associated with fire growth rate in this study.

RSET usually constitutes of three components: fire detection time, pre-movement time and movement time, i.e.:

$$
R S E T=t_{\text {det }}+t_{\text {pre }}+t_{\text {move }} .
$$

For detection time, the smoke detection system is assumed to be activated as the smoke height descends below the ceiling by $5 \%$ of the compartment height (He et al. 2002b). For manual detection success, the detection time is assumed to occur when the smoke layer height descends below the ceiling by $10 \%$ of the compartment height. For the scenario where manual detection fails, the time when the smoke layer height descends below the ceiling by $15 \%$ of the compartment height is assumed to be the detection time (Chu, Sun 2008). The detection times for these three scenarios can be calculated by the following equation:

$$
t_{\text {det }}=\left[\frac{\left(\beta^{-\frac{2}{3}}-1\right) H_{\text {room }}{ }^{-\frac{2}{3}} A_{\text {room }}}{0.0227 \alpha^{\frac{1}{3}}}\right]^{\frac{3}{5}},
$$

where: $\beta$ is $0.95,0.9$ and 0.85 , corresponding to activation of the smoke detection system, manual detection and failure of manual detection, respectively.

As stated above, the evacuation time mainly depends on the human behaviour. The determination of human behaviour in fires has been studied approximately for 40 years (Bryan 2002a). Some typical human behaviour in fire, such as reentry (Bryan 2002b), panic behaviour (Paulsen 1984) and occupant cluster phenomenon (Bryan, Dinenno 1979), has been identified and studied. Furthermore, different types of human behavioural models are developed such as the behaviour sequence model (Canter et al. 1980), the role-rule model (Tong, Canter 1985), the affiliative model (Sime 1985), and social influence model (Deutsch, Gerard 1955).

Pre-movement time is influenced by occupant characteristics, such as gender, emergency training level, age and occupant location (Zhao et al. 2009). This causes a variation in pre-movement time from individual to individual. Previous studies suggest that pre-movement time should be characterized by a probabilistic distribution rather than a deterministic value. Some research results have confirmed that pre-movement time is a variable following a probability distribution, but the specific probabilistic distribution form is still unknown. Previous studies indicate that a Weibull distribution (Maclennan et al. 1999), log-normal distribution (Bensilum, Purser 2002) or normal distribution (Chu et al. 2006; Chu, Sun 2006) may be suitable for characterizing pre-movement time. In this study, normal distribution is employed to characterize the pre-movement time. 
Table 3. Uncertain parameters with their statistical parameters

\begin{tabular}{lccccc}
\hline \multicolumn{1}{c}{ Parameter } & Distribution & $\mu$ & $\sigma$ & Range & Reference \\
\hline Fire growth rate & Log-normal & -5.4 & 1.9 & {$[0.029,0.1879]$} & Holborn et al. 2004 \\
Pre-movement time & Normal & 210 & 70 & {$[20,420]$} & Jia et al. 2002 \\
Occupant density & Normal & 0.35 & 0.09 & {$[0.1,0.6]$} & Zhang, Jing 2004 \\
Occupant flow of exit & Uniform & - & - & {$[1,2]$} & Polus et al. 1983; Fruin 1971 \\
\hline
\end{tabular}

For the value of pre-movement time, there have been extensive investigations by evacuation drills and post fire interviews (Gwynne et al. 2003; Fahy, Proulx 2001; Gwynne, Boswell 2009). Since the focus of this paper is the method of linking safety factor and the probability of failure and the case study is only employed to demonstrate this method, no investigation of premovement time is conducted here. Instead, the investigation results of pre-movement time for Chinese occupants conducted by Jia et al. (2002) are employed here. The statistical parameters are shown in Table 3.

There are essentially two methods available for calculating movement time during the evacuation, the more traditional analytical calculation approach and that which incorporates the use of evacuation models (Papinigis et al. 2010). Although evacuation models can provide more accurate results, especially in highly populated buildings with irregular geometry, a longer time than the analytical calculation is required to obtain the results, especially when the continuous evacuation models, such as FDS+EVAC, Building EXODUS, are used. As a single regular-shaped room is analysed in this case, and Monte Carlo Simulation requires thousands of model runs, for the sake of efficient calculation, the traditional analytical calculation approach using an empirical formula (Melinek, Booth 1975; Togawa 1955) is employed here:

$$
t_{\text {eva }}=\frac{q \cdot A}{f \cdot W},
$$

where: $q$ is the occupant density, person $/ \mathrm{m}^{2} ; A$ is the area of the compartment, $\mathrm{m}^{2} ; f$ is the occupant flow rate per unit exit width, person $/(\mathrm{m} \cdot \mathrm{s}) ; W$ is the width of the exit, $\mathrm{m}$. It should be noted that when the occupants move through the exit, they usually prefer maintaining a distance between themselves and the object in question such as a wall. Hence, the concept of effective width (Gwynne, Rosenbaum 2008) should be employed in the practical fire safety engineering design especially when occupants move through a corridor or passageways. However, as the case presented in this study is on a hypothetical basis and the geometry in this study is only a single fire compartment with doors, the value of the width has little influence on the results. Hence, the effective width is not employed here.

For a specific compartment, the area of the compartment and the width of exit can be considered as deterministic. Therefore, only uncertainties concerning occupant density and flow of exit are considered here. The distribution form and range of these uncertain parameters for calculating ASET and RSET are summarized in Table 3.

\subsection{Determining the corresponding safety factor for each fire scenario}

Having determined the target probability of failure and the limit state equation for each fire scenario, the next step is to calculate the corresponding safety factor according to the procedure described in Section 2.3. As shown in Table 2, the target probability of failure for each fire scenario is very small; in order to obtain a good estimate of the corresponding safety factor, the Monte Carlo Simulation sample size should be sufficiently large. To ensure that an adequate Monte Carlo simulation sample size is used in this study, a sample size dependence analysis was conducted. Taking Fire Scenario 1 as an example, the analysis independently generated twenty groups of samples from the variables in Table 3 . The sample sizes were $10000,20000, \ldots, 200000$. The relative differences in these safety factors when using different sized samples are shown in Figure 6. It may be concluded that when the sample size exceeds 170000 , there is no correlation between sample size and the value of safety factors with the LHS technique. In order to ensure sufficient accuracy, a sample size of $N=300000$ is used in the subsequent calculation.

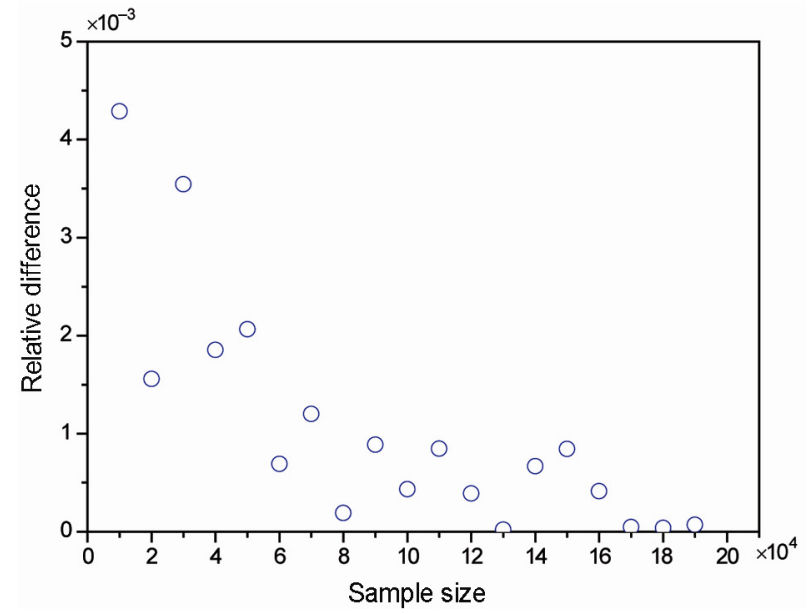

Fig. 4. The relative difference of safety factors with twenty different sample sizes for Scenario 1

The safety factor calculated for each fire scenario is as shown in Table 4. From these data it may be concluded that, when the risk of failure of all fire protection systems is combined, the target probability of failure in Scenario 1 is largest. In order to address such a target probability of failure, the largest safety factor should be assigned to this fire scenario. Though the target probability of failure is different for Scenario 2 and 3, the safety factors are almost the same. The difference between Scenarios 2 and 3 lies in the issue of whether the automatic smoke detection 
and alarm systems operate successfully or not. The resulting minor difference in safety factors between these two scenarios suggests that the influence of automatic smoke detection and alarm systems when determining safety factors can be ignored in this case study. It should further be noted that there is no need to calculate the safety factor for Scenario 4. The reason is that the sprinkler system in Scenario 4 operates successfully, which implies that the fire can be successfully controlled or extinguished by sprinklers, and no casualties will occur. In this case, the actual probability of failure can be regarded as 0 , which is smaller than the target probability of failure.

Table 4. Safety factors with corresponding target failure probabilities

\begin{tabular}{ccc}
\hline Fire scenario & Target failure probability & Safety factor \\
\hline 1 & $7.28 \times 10^{-3}$ & 1.87 \\
2 & $3.24 \times 10^{-3}$ & 1.84 \\
3 & $8.49 \times 10^{-4}$ & 1.83 \\
4 & $4.60 \times 10^{-5}$ & - \\
\hline
\end{tabular}

Another thing that should be noted is that the ASET/RSET method, which is currently employed in fire engineering analysis, is a simple approximation of the evacuation process. This method ignores the wide variation in capabilities and physical conditions of occupants in fires, i.e. human behaviour in fires, and assumes that occupants evacuate in a robotic manner. However, the human behaviour in fires is actually very complex, occupants do not evacuate in a robotic manner and their evacuation time may be much longer than that predicted by the robotic manner (Babrauskas et al. 2010; Chow 2013). How to incorporate human behaviour in fire into the calculation of RSET is an important topic that should be studied in future.

\section{Conclusions}

A method of linking safety factor and probability of failure in building fire safety engineering is presented in this article. This method enables fire safety engineers to calculate the margin by which a design incorporating a given safety factor has failed and to determine the changes which must be made to satisfy the required safety level in practical PFPD and fire risk assessment. Moreover, this method provides the fire safety engineers with a guide in selecting an appropriate safety factor to meet the required probability of failure. In order to select reasonable fire scenarios, an event tree is constructed, with consideration of the reliability of fire protection systems. Expected risk to life is integrated to determine the target probability of failure. The safety factor is treated as a random variable, with consideration of ASET and RSET uncertainties. A specific safety factor, whose cumulative probability corresponds to the target probability of failure, can be then found on its distribution. When calculating the safety factor, Monte Carlo simulation using LHS is employed. Due to the small target probability of failure, thousands of samples are required to obtain sufficiently accurate safety factor values. To demonstrate this method in detail, a case study is presented. Sample size dependence analysis is conducted before the safety factor is calculated.

It should be noted that this represents only the first attempt to combine safety factor and probability of failure: further studies should be conducted in the future.

Firstly, given the thousands of model runs conducted in this study, the zone model was employed to calculate ASET and an analytical calculation by empirical formula was used to determine movement time. Due to the limited accuracy of zone models and empirical evacuation formulae, the calculated safety factor is likely to be less accurate than that of field fire and advanced evacuation models. Further research should consider how to employ more complex fire and evacuation models while maintaining an acceptable computation cost, in order to obtain more accurate safety factors using this method.

Secondly, because of the simplicity and efficiency of LHS, Monte Carlo Simulation using LHS was adopted to calculate the safety factor corresponding to the target probability of failure. Though LHS is simple and efficient, a sample size of 200000 was still required in this study to obtain sufficiently accurate safety factors values, since the target probability of failure is very small. The question of how to obtain a sufficiently accurate safety factor with a minimal number of simulation runs is important for the practical application of this method in fire safety engineering.

Last but not least, this study considers some uncertainties when calculating ASET and RSET. However, fire dynamics and human behaviour during evacuation from fires are highly complex and involve many uncertainties. Further studies should incorporate a considerable range of uncertainties, especially the human behaviour in fires, into ASET and RSET calculation to determine more accurate safety factors corresponding to the target probability of failure for reasonable PFPD results.

\section{References}

Babrauskas, V.; Fleming, J.; Don Russell, B. 2010. RSET/ ASET, a flawed concept for fire safety assessment, Fire and Materials 34(7): 341-355. http://dx.doi.org/10.1002/fam.1025

Bensilum, M.; Purser, D. 2002. Gridflow: an object-oriented building evacuation model combining pre-movement and movement behavior for performance-based design, in Proceedings of the Seventh International Symposium on Fire Safety Science, 16-21 June, 2002, Massachusetts, USA. 941 p.

British Fire Protection Systems Association. 2003. Application of fire safety engineering principles to the design of buildings. Part 7: probabilistic risk assessment. British Standards Institution, UK.

Bryan, J. 2002a. Behavioral response to fire and smoke, in Dinenno, P. et al. (Eds.). SFPE handbook of fire protection engineering. USA: Society of Fire Protection Engineers, 3-315-3-341.

Bryan, J. 2002b. Review of human behavior on fire, Fire Protection Engineering 16: 6-10.

Bryan, J.; Dinenno, P. 1979. An examination and analysis of the dynamics of the human behavior in the fire incident at Thurston Hall on April 19, 1979. College Park, MD: Uni- 
versity of Maryland, Department of fire protection engineering.

Bukowski, R.; Budnick, E.; Schemel, C. 1999. Estimates of the operational reliability of fire protection systems, in Proceedings of the Third International Conference on Fire Research and Engineering, 4-8 October, 1999, Chicago, USA.

Canter, D.; Breaux, J.; Sime, J. 1980. Domestic, multiple occupancy, and hospital fires, in Canter, D. (Ed.). Fires and Human Behaviour. Chichester: John Wiley \& Sons Ltd.

Chow, W. 2013. Letter to the editor: comment on 'RSET/ ASET, a flawed concept for fire safety assessment' by V. Babrauskas, J. M. Fleming and B. D. Russell, Fire and Materials 37(3): 257-258. http://dx.doi.org/10.1002/fam.2134

Chu, G. 2007. Study on risk assessment method by coupling fire dynamics and statistical theory. PhD Thesis, University of science and technology of China.

Chu, G.; Sun, J. 2006. The effect of pre-movement time and occupant density on evacuation time, Journal of Fire Sciences 24(3): 237-259. http://dx.doi.org/10.1177/0734904106058249

Chu, G.; Sun, J. 2008. Decision analysis on fire safety design based on evaluating building fire risk to life, Safety Science 46(7): 1125-1136. http://dx.doi.org/10.1016/j.ssci.2007.06.011

Chu, G.; Sun, J.; Wang, Q.; Chen, S. 2006. Simulation study on the effect of pre-evacuation time and exit width on evacuation, Chinese Science Bulletin 51(11): 1381-1388. http://dx.doi.org/10.1007/s11434-006-1381-0

Deguchi, Y.; Notake, H.; Yamaguchi, J.; Tanaka, T. 2011. Statistical estimations of the distribution of fire growth factor study on risk-based evacuation safety design method, in Proceedings of the Tenth International Symposium on Fire Safety Science, 19-24 June, 2011, Marryland, USA. $1087 \mathrm{p}$.

Deutsch, M.; Gerard, H. 1955. A study of normative and informational social influences upon individual judgment, The Journal of Abnormal and Social Psychology 51(3): 629636. http://dx.doi.org/10.1037/h0046408

Fahy, R.; Proulx, G. 2001. Toward creating a database on delay times to start evacuation and walking speeds for use in evacuation modeling, in $2^{\text {nd }}$ International Symposium on Human Behaviour in Fire, March, 2001, Boston, USA. $175 \mathrm{p}$.

Fire Service Bureau, Minstriy of Public Security 1998-2004. Fire statistical yearbook of China (in Chinese). China Personnel Press.

Frantzich, H. 1998. Risk analysis and fire safety engineering, Fire Safety Journal 31(4): 313-329. http://dx.doi.org/10.1016/S0379-7112(98)00021-6

Fruin, J. 1971. Pedestrian planning and design. Metropolitan Association of Urban Designer and Environmental Planners.

Guo, T.; Fu, Z. 2007. The fire situation and progress in fire safety science and technology in China, Fire Safety Journal 42(3): 171-182. http://dx.doi.org/10.1016/j.firesaf.2006.10.005

Gwynne, S.; Boswell, D. 2009. Pre-evacuation data collected from a mid-rise evacuation exercise, Journal of Fire Protection Engineering 19(1): 5-29.

http://dx.doi.org/10.1177/1042391508095093

Gwynne, S.; Galea, E.; Parke, J.; Hickson, J. 2003. The collection and analysis of pre-evacuation times derived from evacuation trials and their application to evacuation modelling, Fire Technology 39(3): 173-195. http://dx.doi.org/10.1023/A:1024189414319
Gwynne, S.; Rosenbaum, E. 2008. Employing the hydraulic model in assessing emergency movement, in Dinenno, P. et al. (Eds.). SFPE handbook of fire protection engineering. USA: Society of Fire Protection Engineers.

Hadjisophocleous, G.; Benichou, N.; Tamim, A. 1998. Literature review of performance-based fire codes and design environment, Journal of Fire Protection Engineering 9(1): 12-40. http://dx.doi.org/10.1177/104239159800900102

He, Y. 2010. Linking safety factor and failure probability for fire safety engineering, Journal of Fire Protection Engineering 20(3): 199-217. http://dx.doi.org/10.1177/1042391510372726

He, Y.; Horasan, M.; Taylor, P.; Ramsay, C. 2002a. Stochastic modeling for risk assessment, in Procedings of the $7^{\text {th }}$ International Symposium on Fire Safety Science, 16-21 June, 2002, Massachusetts, USA. 333 p.

He, Y.; Wang, J.; Wu, Z.; Hu, L.; Xiong, Y.; Fan, W. 2002b. Smoke venting and fire safety in an industrial warehouse, Fire Safety Journal 37(2): 191-215. http://dx.doi.org/10.1016/S0379-7112(01)00045-5

Holborn, P.; Nolan, P.; Golt, J. 2004. An analysis of fire sizes, fire growth rates and times between events using data from fire investigations, Fire Safety Journal 39(6): 481524. http://dx.doi.org/10.1016/j.firesaf.2004.05.002

Jia, C.; Liu, C.; Xiang, T.; Zeng, D. 2002. The study of evacuation start time in fires, Fire Safety Science 11: 176-179. (in Chinese).

Maclennan, H.; Regan, M.; Ware, R. 1999. An engineering model for the estimation of occupant premovement and or response times and the probability of their occurrence, Fire and Materials 23(6): 255-263.

http://dx.doi.org/10.1002/(SICI)1099-1018(199911/12)23: $6<255:$ :AID-FAM697>3.3.CO;2-J

Magnusson, S.; Frantzich, H.; Harada, K. 1996. Fire safety design based on calculations: uncertainty analysis and safety verification, Fire Safety Journal 27(4): 305-334. http://dx.doi.org/10.1016/S0379-7112(96)00050-1

Mckay, M.; Beckman, R.; Conover, W. 1979. A comparison of three methods for selecting values of input variables in the analysis of output from a computer code, Technometrics 21(2): 239-245. http://dx.doi.org/10.2307/1268522

Melinek, S.; Booth, S. 1975. An analysis of evacuation times and the movement of crowds in buildings. Building Research Establishment, Fire Research Station, UK.

Morgan, H. 1998. Sprinklers and fire safety design, Fire Safety Engineering 5: 16-20.

Myers, R.; Montgomery, D. 2002. Response surface methdology. John Wiley \& Sons Ltd.

Nelson, H.; Mowrer, F. 2002. Emergency movement, in Dinenno, P. et al. (Eds.). SFPE handbook of fire protection engineering. USA: Society of Fire Protection Engineers, 3-367-3-380.

NFPA. 1998. NFPA 204 guide for smoke and heat venting-1998 edition. National Fire Protection Association.

Ohmiya, Y.; Tanaka, T.; Notake, H. 2002. Design fire and load density based on risk concept, Journal of Architecture, Planning and Environmental Engineering (Transactions of $A J)$ (551): 1-8.

Papinigis, V.; Geda, E.; Lukošius, K. 2010. Design of people evacuation from rooms and buildings, Journal of Civil Engineering and Management 16(1): 131-139.

http://dx.doi.org/10.3846/jcem.2010.12

Paulsen, R. 1984. Human behavior and fires: an introduction, Fire Technology 20(2): 15-27. http://dx.doi.org/10.1007/BF02384147 
Peacock, R.; Jones, W.; Bukowski, R. 1993. Verification of a model of fire and smoke transport, Fire Safety Journal 21(2): 89-129. http://dx.doi.org/10.1016/0379-7112(93)90038-R

Polus, A.; Schofer, J.; Ushpiz, A. 1983. Pedestrian flow and level of service, Journal of Transportation Engineering 109(1): 46-56. http://dx.doi.org/10.1061/(ASCE)0733947X(1983)109:1(46)

Qu, X.; Haftka, R. 2004. Reliability-based design optimization using probabilistic sufficiency factor, Structural and Multidisciplinary Optimization 27(5): 314-325. http://dx.doi.org/10.1007/s00158-004-0390-3

Ramachandran, G. 1995. Probability-based building design for fire safety: part 2, Fire Technology 31(3): 355-368. http://dx.doi.org/10.1007/BF01039195

Sekizawa, A. 2005. Fire risk analysis: its validity and potential for application in fire safety, in $8^{\text {th }}$ International Symposium Proceedings on Fire Safety Science, 18-23 September, 2005, Beijing, China. 85 p.

Sime, J. 1985. Movement toward the familiar person and place affiliation in a fire entrapment setting, Environment and Behavior 17(6): 697-724. http://dx.doi.org/10.1177/0013916585176003
Tanaka, T. 2011. Integration of fire risk concept into performance-based evacuation safety design of buildings, in $10^{\text {th }}$ International Symposium on Fire Safety Science, 19-24 June, 2011, Marryland, USA. 3 p.

Togawa, K. 1955. Study on fire escapes basing on the observation of multitude currents. Building Research Institute, Ministry of Construction, Japan.

Tong, D.; Canter, D. 1985. The decision to evacuate: a study of the motivations which contribute to evacuation in the event of fire, Fire Safety Journal 9(3): 257-265. http://dx.doi.org/10.1016/0379-7112(85)90036-0

Zhang, S.; Jing, Y. 2004. Research of evacuation crowd in the business hall of large department stores (Chinese), Fire Science and Technology 23: 133-136.

Zhao, C.; Lo, S.; Zhang, S.; Liu, M. 2009. A post-fire survey on the pre-evacuation human behavior, Fire Technology 45(1): 71-95. http://dx.doi.org/10.1007/s10694-007-0040-6

Depeng KONG. PhD candidate specializing in Fire Safety Engineering at the State Key Laboratory of Fire Science in University of Science and Technology of China. His research interests include fire risk assessment methodology and uncertainty analysis.

Shouxiang LU. Professor at the State Key Laboratory of Fire Science in University of Science and Technology of China. His research interests include fire risk assessment methodology, ship safety engineering, dynamic of vapour cloud fire and explosion.

Håkan FRANTZICH. Associate Professor at the Department of Fire Safety Engineering and System Safety in Lund University, Sweden. His research interests include tunnel fire and evacuation.

S. M. LO. Professor at the Department of Civil and Architectural Engineering in City University of Hong Kong. His research interests include spatial planning for pedestrian flow traffic and evacuation modelling, real estate and building development, and fire safety engineering. 